\title{
Prevention and early management of acute renal failure
}

\author{
R. G. LuKe A. C. KenNedy \\ University Department of Medicine and the Artificial Kidney Unit, \\ The Royal Infirmary, Glasgow
}

ACUTE renal failure remains an important complication of many serious medical, surgical and obstetrical conditions. It still carries a considerable mortality, especially after trauma or surgery (Kennedy et al., 1963a; Merrill, 1965a; Shackman, 1966; Stewart et al., 1966).

A suitable working definition of acute renal failure might be renal failure of sudden onset as manifested by insufficient bladder urine to prevent rising blood levels of nitrogenous end-products. This definition intentionally avoids defining acute renal failure purely in respect of urine volume since oliguria, although usually present, is not an invariable feature (Sevitt, 1959). Bladder urine means that acute retention is excluded. The only way to avoid overlooking the diagnosis of acute renal failure is to practise persistent vigilance in the presence of the appropriate clinical circumstances; these circumstances are commonplace in intensive care units.

Acute renal failure may be pre-renal, renal, or post-renal in origin. Either pre-renal failure or postrenal failure may lead to intrinsic renal failure unless treated.

\section{Post-renal failure}

Occult post-renal obstruction must always be considered and, if possible, relieved, since its treatment is usually urological and timely diagnosis is essential to prevent the otherwise inevitable development of secondary renal failure (Kerr, 1956). Ureteric obstruction may be suspected in the presence of an old or recent history of renal stone, gynaecological, urological or pelvic surgery or radiation, or by clinical features of abdominal neoplasia, especially carcinoma of the cervix. Palpably enlarged or tender kidneys are useful diagnostic guides but their absence does not exclude obstructive renal failure. Total anuria is common in post-renal failure whereas it is very unusual in most other forms of acute renal failure, except for acute progressive glomerulonephritis or total renal infarction. In our experience and that of others (Lawrence et al., 1963; Joekes \& Rellan, 1965), the isotope renogram is a useful adjunct to the diagnosis of post-renal failure especially if used soon after the onset of obstruction (Figs. 1 and 2). Unfortunately, from the diagnostic viewpoint, after about 48-72 $\mathrm{hr}$ of total obstruction, as in the experimental animal (O'Connor, Libretti \& Grahack, 1961), the renogram curve may become flat and identical with the intrinsic renal failure pattern, but in our experience this does not necessarily indicate permanent loss of function. We recently observed a patient with calculus ureteric obstruction of 5 days standing who had flat renogram curves (Fig. 2) but

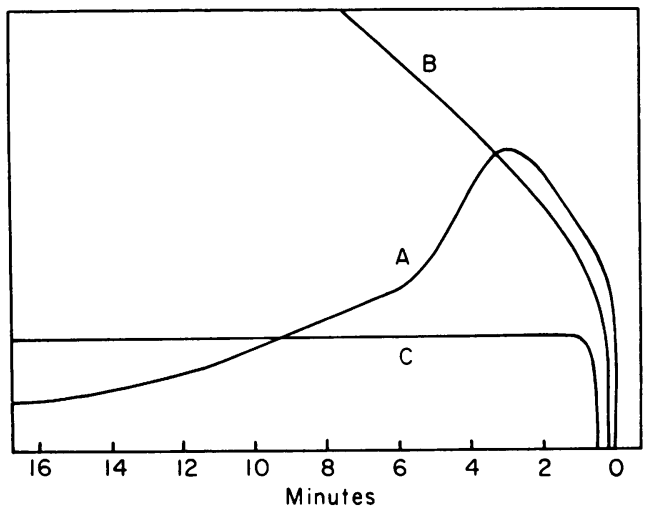

FIG. 1. Diagrammatic representation of isotope renogram tracings from: (A) normal kidney, (B) recent acute post-renal obstruction, and (C) acute intrinsic renal failure.

in whom relief of this obstruction was immediately followed by a diuresis of 6 litres in $18 \mathrm{hr}$.

If post-renal failure is suspected then a straight $\mathrm{X}$-ray of abdomen followed by cystoscopy and retrograde ureteric catheterization is essential. It is sufficient to show that the ureter of one kidney is patent, especially if that kidney is of normal size, as there is always a risk of causing an ascending pyelonephritis. Additional useful information is often obtained by the introduction of $5-10 \mathrm{ml}$ of dye to delineate calyceal pattern and to assist in determination of kidney size and cortical thickness. In some cases, especially in retroperitoneal fibrosis, mere insertion of a ureteric catheter (Utz \& Henry, 
1966) permits urine to flow as the cause of obstruction may be loss of ureteric peristalsis due to fibrous infiltration of the ureter. We have been impressed on several occasions by how silent a carcinoma of cervix may be and consider that a pelvic examination is mandatory in women with unexplained anuria.

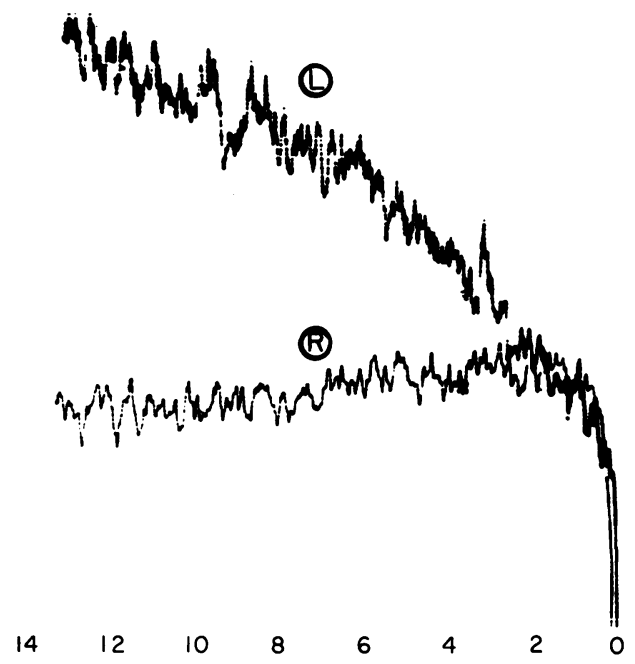

Fig. 2. Isotope renogram from a patient (Mrs Y.) with recent obstruction of the (L) ureter and severe impairment of function in the (R) kidney. The patient had cystinuria and had had several operations for removal of cystine calculi from the (R) kidney and ureter. She presented with oliguria, fever, (L) loin pain, an infected urine and a blood urea of $200 \mathrm{mg} / 100 \mathrm{ml}$; straight X-ray of abdomen was negative but because of the renogram appearance (L) retrograde catheterization was performed and there was an immediate diuresis, with return of the blood urea to normal. The renogram curve on the (L) side returned to normal but that on the (R) has not changed

In some cases of post-renal failure a preliminary haemodialysis or peritoneal dialysis is required to control azotaemia before diagnostic steps can be undertaken or surgical treatment effected; if, however, a diuresis follows relief of obstruction, correction of uraemia is usually rapid, and correction of electrolyte abnormalities easy, because of the higher fluid intake permissible.

\section{Pre-renal and renal failure}

Diminished circulating blood volume or other factors such as anaesthesia (de Wardener, 1961) which lead to lowered renal perfusion produce oliguria by physiological mechanisms; there is increased tubular reabsorption (Berliner \& Davidson, 1957) of the already reduced glomerular filtrate (Kragelund, 1959) and ADH and aldosterone act to reduce urine volume further (Mielke \& Kirklin, 1966). The differential diagnosis of 'physiological' oliguria due to circulatory inadequacy from 'pathological' oliguria due to acute reversible intrinsic renal failure (acute tubular necrosis) in a patient following a period of renal under-perfusion is a difficult clinical problem. The condition of pre-renal or circulatory renal failure shades into the condition of acute reversible intrinsic renal failure (acute tubular necrosis). The two conditions have the same aetiology and there is no rigid dividing line. At one end of the spectrum prompt diuresis follows correction of the aetiological factor while it is being corrected and at the other end oliguria persists despite complete correction of the primary abnormality. In all oliguric patients with deficits of fluid, electrolyte, plasma or blood these deficits must be made good, but where diuresis does not ensue great care must be taken not to 'overshoot' with replacement therapy. Monitoring of central venous pressure is a useful addition to the guidance obtained from history, skin turgor, pulse, blood pressure, haematocrit, electrolytes and plasma protein concentration.

\section{Aetiology and terminology}

There are two broad groupings of acute renal failure of renal origin and these differ markedly in prognosis and management. Firstly, there is what is commonly but perhaps erroneously called acute tubular necrosis. This term is inaccurate because the histological changes of acute tubular necrosis correlate poorly with the functional degree of renal failure or even the very presence of functional renal failure (Sevitt, 1959; Finckh, Jeremy \& Whyte, 1962); and even the original classical descriptions of the lesions of acute tubular necrosis by microdissection (Oliver, MacDowell \& Tracey, 1951) applied to only a minority of nephrons in the affected kidneys. A more acceptable term for clinical usage is acute reversible intrinsic renal failure and we shall use this as synonymous with 'acute tubular necrosis'. The condition can usually be diagnosed with reasonable confidence when acute impairment in renal function, usually with oliguria, follows a typical 'onset incident' such as oligaemic or septic shock. The reversibility of the lesion is always initially presumptive. If oliguria persists for more than 21 days from the onset incident in the absence of any second renal insult, then cortical necrosis with nonrecoverable glomerular destruction must be suspected; in our experience this is rare. The mean length of the oliguric phase is 11 days (Loughridge et al., 1960; Kennedy et al., 1963a), although we have experience of considerably longer periods of oliguria with ultimate recovery. Our most recent example was a man of 38 years who developed severe acute reversible intrinsic renal failure following multiple injuries; the oliguria lasted for 38 days, and he required fifteen haemodialyses, but renal function is now normal. 
The aetiology of acute reversible intrinsic renal failure is clinically diverse (Merrill, 1965b) but usually consists of a combination in varying proportions of two factors, namely, reduced renal blood flow and exposure of the renal parenchyma to toxic substances. Any condition which reduces renal perfusion to a sufficient degree can cause acute reversible intrinsic renal failure, but whether it does so or not in a given patient is quite unpredictable. In many instances, despite the clinical features of severe shock, no renal damage will be sustained, whereas in other patients, for reasons we do not know, acute reversible intrinsic renal failure will occur despite apparently mild predisposing circumstances and without recorded hypotension.

The second form of acute renal failure of renal origin occurs secondary to acute progressive glomerulonephritis, to vascular disorders such as polyarteritis nodosa, malignant hypertension or bilateral renal infarction or to infective lesions such as necrotizing papillitis. The prognosis in this category of patients is in general extremely poor. In our series of twenty-one cases of acute progressive glomerulonephritis requiring dialysis there has been only one unassisted long-term survival and this is in accord with experience of others (Harrison, Loughridge \& Milne, 1964; Berlyne \& Baker, 1964). Diagnosis is often suggested by the presence of extra-renal clinical features; renal biopsy is invaluable for confirmation of diagnosis and prognosis.

Early diagnosis of acute reversible intrinsic renal
failure (acute tubular necrosis)
Observation of urine volume and determination of Observation of urine volume and determin of
plasma urea and electrolytes should be a routine after any major infection, trauma, obstetric accident or surgical procedure. The presence of oliguria should alert one to the possibility of acute reversible intrinsic renal failure but where catabolism is particularly severe, as after multiple injuries, urine volume of apparently normal proportions (e.g. 1-1 $\frac{1}{2}$ litres) must not be taken as excluding renal impairment and serial observations of plasma urea should be made. Similar care must be exercised when a high protein intake is being given as in the later stages of the treatment of burns, or head injuries, or pharyngeal, oesophageal or oral surgery. Especially in tube feeding in the elderly it should be remembered for practical purposes that each $3 \mathrm{~g}$ of ingested protein produces $1 \mathrm{~g}$ of urea, that a high urea output produces an osmotic diuresis and that in an older patient under such conditions maximum urine urea concentration may be about $1.5 \mathrm{~g} / 100 \mathrm{ml}$ urine. The diuresis also produces, in the absence of appropriate replacement, water and possibly also sodium depletion which may further impair renal concentrating power. We recently observed an elderly patient with a blood urea of $570 \mathrm{mg} / 100 \mathrm{ml}$, a serum sodium of $156 \mathrm{mEq} / \mathrm{l}$ and urine volume around 1.51 /day who had been receiving via stomach tube approximately $300 \mathrm{~g}$ of protein per $24 \mathrm{hr}$ in the form of a well-known proprietary protein supplement. Vigorous infusion of $5 \%$ dextrose water produced urine volumes of over $51 /$ day and a rapid drop in blood urea to normal levels.

In our experience there are certain high risk situations for the development of acute reversible intrinsic renal failure. These are after gall bladder surgery where there has been inadvertent leak of bile, acute pancreatitis, major trauma, especially if there has been a delay in admission to hospital, septic abortion, concealed accidental haemorrhage, and septicaemic states. Whenever oliguria $(20 \mathrm{ml} / \mathrm{hr}$ or less) occurs in other circumstances, and particularly so in these conditions, studies should be initiated to determine whether acute reversible intrinsic renal failure is developing.

A considerable number of diagnostic suggestions have been made to aid in the differentiation of oliguria due to pre-renal circulatory inadequacy and acute reversible intrinsic renal failure.

1. Proteinuria.

2. Urine microscopy.

3. Urine sodium concentration.

4. Urine urea concentration.

5. Urine specific gravity.

6. Blood urea level.

7. Urine/plasma osmolality ratio.

8. Urine/plasma urea ratio.

9. Response to replacement of deficits.

Many of these possible guides would, of course, be less applicable where there was pre-existing renal disease, or in the aged (Sporn, Lancestremere \& Papper, 1962). In our view there is no single laboratory test which is absolutely and invariably diagnostic of acute reversible intrinsic renal failure but we believe that the most useful are a comparison of urine and plasma osmolalities and of urine and plasma urea expressed in $\mathrm{mg} / 100 \mathrm{ml}$.

Maximum urine osmolalities during dehydration in normal subjects lie between $800-1400$ m-osmole/ $\mathrm{kg}$ water (Miles, Paton \& de Wardener, 1954). Concentrating ability is depressed to $400-700$ $\mathrm{m}$-osmole/ $\mathrm{kg}$ water in man during and up to $24 \mathrm{hr}$ after surgery and anaesthesia (Gullick \& Raisz, $1960)$ and in the experimental animal during and soon after trauma (Gann \& Wright, 1966). Reduction of glomerular filtration rate reduces maximum urinary concentrating ability (Levinsky, Davidson \& Berliner, 1959) and this is probably at least one mechanism by which tubular concentrating power is affected in the above situations. In the normal individual, when dehydrated, if one takes the plasma osmolality as $300 \mathrm{~m}$-osmole the urine/plasma osmolality ratio will be $2 \cdot 7-4 \cdot 0$. Eliahou \& Bata 
(1965) take a ratio of greater than 2.0 as meaning definite pre-renal failure and less than 1.70 as meaning that early acute reversible intrinsic renal failure has developed. It is now well established that in the later stages of acute reversible intrinsic renal failure the urine/plasma osmolality ratio approximates to 1 (Bull, Joekes \& Lowe, 1950; Roscoe, 1964).

A urine/plasma urea ratio of greater than 20:1 (Perlmutter et al., 1959) almost always implies that the oliguria is still a physiological renal response and that diuresis will follow correction of the primary abnormality and of fluid and other deficiencies. The urine specimen must be fresh, or immediately refrigerated, as results are invalid in the presence of urea-splitting organisms in the urine. The ratio must be used early in the course of the renal failure to be of most diagnostic significance as it will undoubtedly be lowered by a high blood urea and the limitations of the renal concentrating ability for urea (around $4000 \mathrm{mg} / 100 \mathrm{ml}$ in the normal adult when dehydrated). In our experience and that of others (Eliahou, 1964) the ratio falls to around 5 or lower in the later established stages of acute reversible intrinsic renal failure. A ratio of less than $14: 1$ is strongly suggestive of, while a , ratio of 10:1 should imply the onset of acute reversible intrinsic renal failure (Perlmutter et al., 1959).

It is important that these indices are considered in relation to urine volume as obviously in the face of high urine volumes the ratios will fall in the absence of renal impairment. Lindsay, Linton \& Longland (1965) attempt to allow for urine volume in their concept of a renal excretory index* which they find useful to assess the significance of oliguria in the immediate post-operative period.

The urine specific gravity (SG) is a much less exact diagnostic guide but a SG of less than 1.014 suggests acute reversible intrinsic renal failure (Shackman, Milne \& Struthers, 1960) and more than 1.016 pre-renal oliguria. Molloy (1962) prefers the use of the urine urea concentration to the SG and states that if the urine urea is less than $1100 \mathrm{mg} /$ $100 \mathrm{ml}$ in the oliguric post-operative patient 'acute tubular necrosis' may be predicted.

The published observations regarding urine sodium concentration are at some variance. Bull et al. (1950) reported that the urine sodium concentration was high in 'acute tubular necrosis' whereas Graber \& Sevitt (1959) found that in burned patients with 'acute tubular necrosis' the urine sodium was low. Levinsky (1966) suggests that a urine sodium concentration below $15 \mathrm{mEq} / \mathrm{l}$ suggests pre-renal failure and helps to differentiate the condition from 'acute

* Renal excretory index $=\frac{U u}{B u} \times \frac{24 \mathrm{hr} \text { urine volume }}{100}$

An index of less than 80 indicates acute reversible intrinsic renal failure. tubular necrosis'. Roscoe (1964) and Platts (1966) reported that the urine sodium concentration may vary very widely in different patients with 'acute tubular necrosis' and the range of levels found $(10-110 \mathrm{mEq} / \mathrm{l})$ is such that it is questionable whether much stress should be laid on the finding. It is certainly our experience that it is of little diagnostic value.

Though some have claimed (Levinsky, 1966) that the detection of renal tubular cells by urine microscopy is helpful in differentiating pre-renal oliguria from acute reversible intrinsic renal failure we, using a quantitative method of microscopy (McGeachie \& Kennedy, 1963), have not found it so. Proteinuria is not a helpful finding in differentiation since it may be present in pre-renal circulatory inadequacy as well as in 'acute tubular necrosis'.

The level of blood urea is not, by itself, of value in differentiating the two conditions in the early stages since in pre-renal failure (defined as responding to replacement of deficits) it can be much higher than is generally realized. We have already referred to a blood urea level of almost $600 \mathrm{mg} / 100 \mathrm{ml}$ in a dehydrated patient with an extremely high protein intake. We have also seen a blood urea level of $420 \mathrm{mg} / 100 \mathrm{ml}$ in a man with a gross water and salt deficit (serum chloride level $37 \mathrm{mEq} / \mathrm{l}$ ) arising after gastric surgery; he produced a diuresis of over 5 litres in the first $24 \mathrm{hr}$ of vigorous fluid and electrolyte replacement and the blood urea fell rapidly to reach $50 \mathrm{mg} / 100 \mathrm{ml}$ in $72 \mathrm{hr}$.

\section{Prevention of acute reversible intrinsic renal failure (acute tubular necrosis)}

Prevention of acute reversible intrinsic renal failure commences with the early and efficient treatment of the primary abnormality, be it surgical, medical or obstetric, causing the reduced renal blood flow. Reference has already been made to the importance of prompt correction of deficits of fluid, electrolyte, plasma and blood. More detailed accounts of the management of shock are given elsewhere in this symposium. Especially in elderly patients cardiac failure is often a contributory, if seldom a primary aetiological factor in the genesis of pre-renal failure and the use of digoxin should always be considered. Dosage of digoxin should be reduced to about half the usual in oliguric patients in view of the decrease in renal excretion (Doherty, Perkins \& Wilson, 1964). Occult severe infection, usually with Gram-negative bacteria with endotoxin shock but sometimes with staphylococci or other organisms, must always be considered in any unexplained case of shock and an appropriate antibiotic used pending the results of blood culture (Spink, 1962; Weinstein \& Klainer, 1966). In our experience cephaloridine is often extremely valuable in the absence of specific pointers to therapy. 


\section{Mannitol}

The literature on mannitol is now very extensive and we can give only a brief account of the salient features, with emphasis on practical therapeutic issues. These can best be discussed under three headings.

(1) Mannitol therapy in the patient who is oliguric after a potential renal insult.

(2) 'Prophylactic' mannitol therapy prior to and during high risk situations.

(3) Mannitol therapy in oliguria due to nephrotoxins such as certain drugs, chemicals and pigments.

There is a growing opinion that the administration of mannitol in the early stages of acute reversible intrinsic renal failure can prevent the establishment of the lesion in a substantial proportion of cases. It is, of course, extremely difficult to prove, as Moore (1963) has pointed out, that a therapeutic measure prevents the development of a lesion which, as already stated, is quite unpredictable in its development in the absence of such treatment, but there is now a very wide support for its use from a considerable number of workers with an extensive clinical experience of acute renal failure (Barry, Mazze \& Schwartz, 1964; Eliahou, 1964; Luke et al., 1965; Moore, 1963; Mueller, 1965; Nesbit et al., 1962; Powers et al., 1964). Of these groups, Barry and his colleagues have perhaps done most to establish the therapeutic usefulness of mannitol. We have seen oliguria reversed so abruptly after infusion of mannitol in patients in whom oliguria has persisted after correction of the primary abnormality (Fig. 3) and in whom the urine/plasma osmolality and urea indices indicated intrinsic renal impairment that we are convinced of its efficacy. To support the extensive circumstantial clinical evidence in favour of mannitol there is abundant well-controlled animal experimentation that mannitol has a protective action on the kidney during and soon after renal insults as diverse as adrenaline infusion into the renal artery (Hatcher, Gagnon \& Clarke, 1958) and intravenous administration of bacterial endotoxin and red cell lysate (Hoffmeister, Regelson \& Wilkens, 1965). We believe that the cumulative evidence in favour of mannitol to be so strong that a double-blind trial in early acute reversible intrinsic renal failure is unethical; this is particularly so in view of the lack of toxicity of mannitol used in the manner to be described.

In our experience (Luke et al., 1965) mannitol was effective in patients with oliguria and a urine/plasma urea ratio of less than 14:1 only when given within $50 \mathrm{hr}$ of the onset incident and when there was not a glomerular lesion. Eliahou \& Bata (1965) found that in patients with early 'acute tubular necrosis' they could clearly separate those that responded to mannitol (a mean urine/plasma osmolality ratio of
1.35 with a ratio of $1 \cdot 14-1.74)$ from those who did not (a mean urine/plasma osmolality ratio of 1.04 with a range of 0.97-1.07); they did not discuss the time-lapse after the onset incident. We are in broad agreement with them about the importance of the urine/plasma osmolality ratio but have obtained a diuresis with mannitol in one case at $40 \mathrm{hr}$ after the onset incident with a ratio of 1.05 and failed to obtain a response with ratios of 1.30 and 1.33 in two patients 4 days after the onset incident. Conversely, we have seen a patient with superior mesenteric artery thrombosis and continuing shock in whom the ratio was 1.05 within $24 \mathrm{hr}$ after the

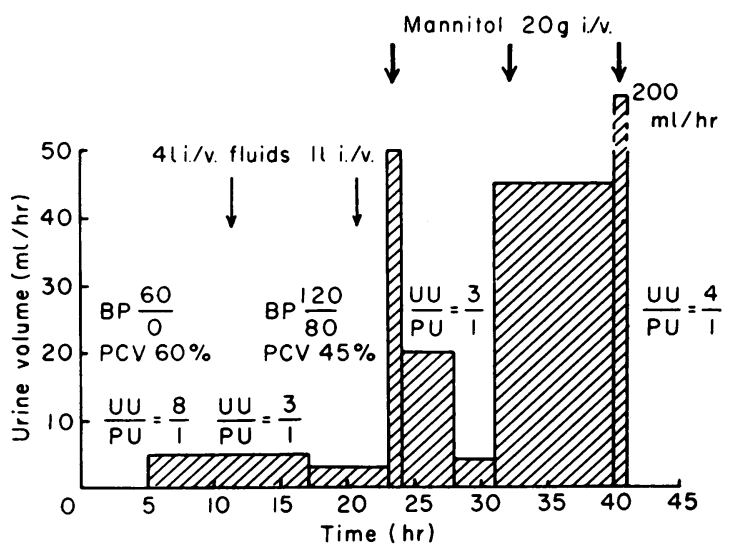

FIG. 3. Example of mannitol-induced diuresis in a patient (Mrs E.T., 74 years old) with persistent oliguria despite correction of water and salt deficit. The patient had had persistent vomiting due to pyloric stenosis and was clinically shocked on admission. Note that, after correction of hypotension, further infusion of 1000 $\mathrm{ml}$ of fluid $(500 \mathrm{ml} 5 \%$ dextrose and $500 \mathrm{ml}$ normal saline) produced no rise in urine volume for a further 3 $\mathrm{hr}$, but that a diuresis followed the subsequent use of mannitol.

incident who did not diurese with mannitol. In our view it is important to consider the time factor as well as the urine/plasma ratios in assessing the possibility of attaining a response to mannitol in oliguric patients.

In clinical practice when dealing with an oliguric patient following an actual or potential renal insult we adopt the following procedures.

(1) Correction of fluid, electrolyte and other deficits and prompt treatment of infection.

(2) Measurement of urine/plasma urea and osmolality ratios.

(3) If the urine/plasma osmolality ratio is less than 2:1 and/or the urine/plasma urea ratio is less than 14:1 insertion of an indwelling bladder catheter, with closed drainage to permit observation of hourly urine volumes. The catheter is removed as soon as it is clear that a satisfactory response to mannitol has occurred or, alternatively, that no response has 
occurred and the bladder is washed out with a 1 in 10,000 solution of chlorhexidine.

(4) If less than $50 \mathrm{hr}$ have elapsed from the onset incident and if the urine/plasma osmolality ratio is greater than 1.15 and/or the urine/plasma urea ratio is less than 14:1 give up to three doses of $100 \mathrm{ml}$ of $20 \%$ mannitol intravenously each over $10-20 \mathrm{~min}$ at 2 -hr intervals until the urine volume is at least $50 \mathrm{ml} / \mathrm{hr}$. As the time from the 'onset incident' reaches and then increases over $50 \mathrm{hr}$ and as the urine/plasma osmolality ratio approaches and then falls below 1.15 the chances of a response to mannitol decrease sharply. In borderline cases a trial may be made (e.g. $20 \mathrm{~g}$ possibly repeated once) but there is no point in persevering with mannitol if there is no definite response.

(5) If the urine volume does not increase following mannitol given as above, establish conservative regimen for acute reversible intrinsic renal failure.

(6) If following an 'onset incident' there is oliguria but the renal indices show maintained renal function we prefer not to give mannitol as it will produce a loss of water and sodium which may not be beneficial at the moment; if and when the renal indices show deterioration then mannitol is given as above.

(7) If there is evidence of fluid deficit and the indices are indicative of acute reversible intrinsic renal failure then mannitol should not be given until fluid replacement is at least well under way.

When there is a diuresis with mannitol the osmolality and urea indices do not usually change initially but we and others (Eliahou, 1964) have found that there is frequently a marked rise in the ratios of both indices some $24-48 \mathrm{hr}$ later suggesting recovery of tubular function; occasionally this rise in ratio occurs sooner. In normal hydropenic subjects mannitol infusion causes a drop in urine osmolality (Raisz \& Scheer, 1959). In the later stages of established acute reversible renal failure the urine/plasma osmolality ratio is always less than 1.10 and the urine/plasma urea ratio is usually less than $5: 1$.

Mannitol can also force an osmotic diuresis in situations of physiological oliguria after surgery, and since as well as the volume of experimental evidence from animal work (Mueller, 1965) there is excellent clinical evidence (Barry, Mazze \& Schwartz, 1964) that a normal or high urine flow is protective against the development of acute reversible intrinsic renal failure, mannitol can be used with advantage in high risk situations such as abdominal vascular surgery near the renal arteries (Barry et al., 1961; Luck \& Irvine, 1965), during operations on jaundiced patients (Dawson, 1964), or heart-lung by-pass (Etheredge et al., 1965) although there are contrary views (Beall et al., 1965).

The third situation in which mannitol is of value is in oliguria due to nephrotoxins, some of which may be associated with tubular blockage. Examples are sulphonamides, uric acid (Barry et al., 1963), abnormal proteins such as in myelomatosis and after transfusion reactions (Pak, 1963). In carbon tetrachloride (Stewart et al., 1963) and ethylene glycol poisoning it would seem logical to utilize the osmotic diuresis induced by mannitol to reduce the contact of the nephrotoxin with the tubular cells. In all these situations mannitol should be given as soon as possible. A word of caution is necessary regarding the use of low molecular weight Dextran which is often advocated to improve the 'microcirculation' in states of shock. It has been shown that when it is given in such circumstances in the presence of oliguria, intrinsic renal failure with proteinaceous casts in the distal nephron can occur (Wilkinson, Muckle \& Kerr, 1965; Niall \& Doyle, 1966). Mannitol should be used in these circumstances to avoid this complication.

\section{Mode of action of mannitol}

The prophylactic value of mannitol depends on its ability to maintain urine flow in the face of circumstances which would otherwise lead to oliguria since reduced tubular urine flow itself is probably a very important factor in the genesis of acute reversible intrinsic renal failure (Moore, 1963; Mueller, 1965).

However, the manner in which it produces a diuresis in established oliguria with renal indices suggesting early acute reversible intrinsic renal failure is less clear, especially since the cause of the oliguria itself in this situation is not established. It is now clear (Munck, 1964; Reubi et al., 1964) by various techniques of estimating renal blood flow that this approximates one-third to one-half normal in acute reversible intrinsic renal failure in man despite the presence of marked oliguria. Either there is shunting of blood to bypass the glomerulus, or there is a rearrangement of pressures in the afferent and efferent arteriole such that there is no effective filtration pressure; or there is continuing glomerular filtration with total absorption or leakage of the glomerular filtrate. Micropuncture studies (Oken, Arce \& Wilson, 1966) and functional and histological studies (Jaenike, 1966) of haemoglobininduced acute renal failure in the rat suggest that the lesion is due in the first $24 \mathrm{hr}$ to a severe drop in glomerular filtration with reabsorption of the filtrate, but that after 48-72 hr distal nephron obstruction due to casts and tubular debris occurs and causes dilatation of the proximal tubule.

Mannitol, a hexahydric sugar alcohol (molecular weight, 180), is not metabolized in the body, is confined to the extracellular fluid (ECF) compartment, filtered at the glomerulus, and is not reabsorbed by the renal tubule; because of its low molecular weight 
it has a potent osmotic effect. It can maintain urine flow in the experimental animal with haemorrhagic shock at blood pressure levels otherwise associated with anuria and also improves glomerular filtration rate in these circumstances (Murphy, Gagnon \& Teschan, 1963a). This was attributed by these authors (Murphy et al., 1963b) to the 'extra-renal' effects of mannitol by its expansion of ECF space and plasma volume, drop in haematocrit, and hence reduced blood viscosity but other workers (Braun \& Lilienfield, 1963; Goldberg \& Lilienfield, 1965) have shown that mannitol has a direct intrinsic renal vasodilatory effect, possibly on the afferent arteriole, leading to a reduced renal vascular resistance. We have observed mannitol produce a definite diuresis in two patients with acute reversible intrinsic renal failure and an elevated central venous pressure without further increasing it, so that expansion of the ECF does not appear to be an essential part of its action. Mannitol, as well as increasing the rate and volume of tubular flow, dilates the lumina of proximal and distal tubules in the rat (Gottschalk \& Mylle, 1957). It is evident that there are two main effects of mannitol, the renal 'vascular' effect and the tubular 'flushing' effect, either or both of which could be concerned in the reversal of early intrinsic reversible acute renal failure in man.

There are three other related hypotheses for its action. Merrill (1965c) has suggested that the tubular osmotic effect of mannitol prevents the tubule collapsing under the action of the increased interstitial pressure which may be present in acute reversible intrinsic renal failure; Thurau (1964) has suggested that it acts by maintaining urine flow in the region of the macula densa thus interfering with the release of an intrarenal vasoconstrictor, probably angiotensin; and it is possible that the accumulation of ammonia (Wickham \& Sharma, 1965) in the tubule cell is prevented by maintained tubular flow.

The lack of action of mannitol in the later stages of acute reversible intrinsic renal failure may be due to its not being filtered into the tubule, or to its leakage into the renal interstitium through the breaks in the structural continuity of the tubular epithelium described by Oliver et al. (1951) so that there is no longer a differential osmotic effect across the tubular wall.

The infusion of mannitol is safe when given in the way outlined, though great care must be taken in its use where there is cardiac failure, as it does expand the ECF volume. There are histological renal changes after infusion of mannitol in the experimental animal (DiScala et al., 1965), but these were completely reversible and no functional changes were associated.

\section{Treatment of established acute reversible intrinsic renal failure}

It is our experience that the incidence of acute reversible intrinsic renal failure is decreasing probably as a consequence of increased awareness of the various clinical situations which may lead to it and of improved management of 'shock' in all its various aspects. In our opinion the use of mannitol in the circumstances outlined above has also materially contributed to the decline in the number of cases of established acute reversible intrinsic renal failure. It is very unlikely, however, that we shall ever reach a situation where the lesion is totally preventable since, to take only one factor, there will always be cases, e.g. following accidents in remote areas, where uncorrected hypotension has persisted for sufficiently long to allow the renal changes to become established. Again, even without such delay, there are cases where the 'onset incident' is so profound that the renal insult persists over many hours. Indeed, it is our experience, and we believe that of others, that while the total number of cases of established acute reversible intrinsic renal failure decreases the proportion with the more severe forms of the disorder is relatively increased.

Certainly there is no room for a lessening of effort in the management of established acute reversible intrinsic renal failure. This will be discussed in greater detail by Dr Blagg and we shall give only a summary of our current practice, stressing recent developments.

Our own regimen (Kennedy et al., 1963a) followed orthodox lines of careful control of fluid intake, a high carbohydrate-low protein calorie supply, control of hyperkalaemia, anabolic steroids, prevention and early treatment of infection bearing in mind the need for reduced antibiotic dosage, and early mobilization. This regimen has been modified in detail rather than principle. We now rarely use anabolic steroids, we largely rely on $20 \%$ fructose given by peripheral vein as a calorie source when the patient is unable to eat in view of our finding (Luke et al., 1964) that uraemic patients do not show intolerance to fructose as they do to glucose (Fig. 4). We note the advocacy of Berlyne, Janabi \& Shaw (1966) and Berlyne et al. (1966) of a calcium resin as an alternative to the widely used Resonium-A for the treatment of hyperkalaemia in view of the possibility of sodium-overload.

In common with most renal-failure units we now tend to dialyse patients with established acute reversible intrinsic renal failure rather earlier but we have not pursued this to the extent of 'prophylactic' dialysis since this would necessitate such treatment in many relatively uncomplicated cases who recover with only conservative measures after an oliguric phase of modest duration and a blood urea which does not rise above about $250-300 \mathrm{mg} / 100 \mathrm{ml}$. We dialyse if there is clinical symptomatology of uraemia, if there is hyperkalaemia not controlled by resin therapy or other measures, if there is increasing 
metabolic acidosis, and if the blood urea has reached about $300 \mathrm{mg} / 100 \mathrm{ml}$ and is expected to rise further. Estimation of the rate of rise of urea (Parsons \& McCracken, 1959) remains a very valuable guide to the degree of catabolism and to the likelihood of dialysis being required. Wherever possible we now insert an arteriovenous shunt as soon as haemodialysis appears probable and this permits a much more liberal and flexible use of dialysis thereafter.
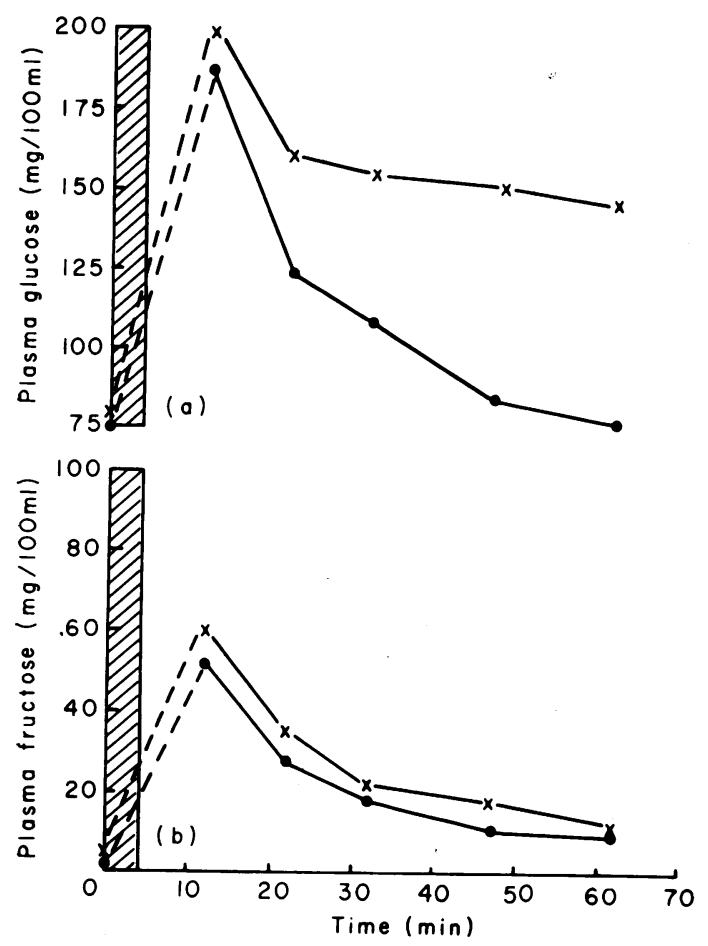

Fig. 4. Normal fructose tolerance compared with the typical delayed clearance of glucose in a uraemic patient. , Normal (case 9); $\times$, uraemic (case 7). Cross-hatching in (a) = infusion of $25 \mathrm{~g}$ glucose; in (b) = infusion of $25 \mathrm{~g}$ fructose. (Figure reproduced by courtesy of Editor of Journal of Laboratory and Clinical Medicine.)

Leaving aside the question of availability of facilities, there is still lack of agreement on the precise merits and indications for haemodialysis and peritoneal dialysis. Stewart et al. (1966) found the incidence of mortality and morbidity associated with each form of therapy to be similar. We have had a considerable experience with both forms of treatment and are of the opinion that haemodialysis with a high efficiency machine (Kennedy et al., 1961) is definitely to be preferred in patients with markedly increased catabolism, especially the post-traumatic cases; we have recorded in detail our experience with a particularly severe example of such a case (Kennedy et al., 1963b) and have briefly referred elsewhere in this article to another patient who required fifteen haemodialyses over 38 days, both with successful outcome. We roytinely employ a high glucose concentration $(1.5 \mathrm{~g} / \mathrm{l})$ in the dialysate to minimize the development of the cerebral disequilibrium syndrome (Kennedy et al., 1964) and, with this, we have never seen a patient lose consciousness or convulse even with fairly rapid correction of uraemia.

Peritoneal dialysis is clearly of value when there is a major difficulty in access to the vascular compartment, when there is need to correct overhydration, and when there is danger of severe bleeding with heparinization; we have not found that regional heparinization invariably prevents this during haemodialysis. We also find a few hours of peritoneal dialysis an extremely useful short-term measure (e.g. over-night) in the emergency admission room pending a semi-elective haemodialysis. We are committed to neither procedure exclusively and use both measures as we think fit. In general, we find that patients who have experienced both forms of dialysis express a clear preference for haemodialysis.

It is important to realize that the experience of the renal failure group is almost always of greater importance than the form of dialysis treatment employed, and we think that there is a real danger, certainly in cases with markedly increased catabolism, in treatment, more often peritoneal dialysis, being carried out by doctors and nurses with an infrequent and limited experience of acute renal failure.

\section{References}

Barry, K.G., Cohen, A., Knochel, J.P., Whelan, T.J., Beisel, W.R., Vargas, C.A. \& LeBlanc, P.C. (1961) Mannitol infusion. II. The prevention of acute functional renal failure during resection of an aneurysm of the abdominal aorta. New Engl. J. Med. 264, 967.

Barry, K.G., Hunter, R.H., Davis, T.E. \& Crosby, W.H. (1963) Acute uric acid nephropathy. Treatment with mannitol diuresis and peritoneal dialysis. Arch. intern. Med. 111, 452.

Barry, K.G., Mazze, R.I. \& Schwartz, F.D. (1964) Prevention of surgical oliguria and renal hemodynamic suppression by sustained hydration. New Engl. J. Med. 270, 1371.

Beall, A.C., Hall, W., Morris, G.C. \& De Bakey, M.E. (1965) Mannitol-induced osmotic diuresis during renal artery occlusion. Ann. Surg. 161, 46.

Berliner, R.W. \& Davidson, D.G. (1957) Production of hypertonic urine in the absence of pituitary antidiuretic hormone. J. clin. Invest. 36, 1416.

Berlyne, G.M. \& BAKER, S.B. DE C. (1964) Acute anuric glomerulonephritis. Quart. J. Med. 33, 105.

Berlyne, G.M., JANABi, K. \& ShaW, A.B. (1966) Dangers of Resonium $A$ in the treatment of hyperkalaemia in renal failure. Lancet, i, 167.

Berlyne, G.M., Janabi, K., Shaw, A.B. \& Hocken, A.G. (1966) Treatment of hyperkalaemia with a calciumresin. Lancet, i, 169.

Braun, W.E. \& Lilienfield, L.S. (1963) Haemodynamic effects of hypertonic mannitol infusion. Proc. Soc. exp. Biol. (N.Y.), 114, 1. 
Bull, G.M., Joekes, A.M. \& Lowe, K.G. (1950) Renal function studies in acute tubular necrosis. Clin. Sci. 9, 379.

Dawson, J.L. (1964) Jaundice and anoxic renal failure: protective effect of mannitol. Brit. med. J. i, 810 .

DE WARDENER, H.E. (1961) The Kidney. An Outline of Normal and Abnormal Structure and Function, p. 205. Churchill, London.

DiScala, V.D., Mautner, W., Cohen, J.A., LevitT, M.F., Churg, J. \& YUNis, S.L. (1965) Tubular alterations produced by osmotic diuresis with mannitol. Ann. intern. Med. 63, 767.

Doherty, J.E., Perkins, W.H. \& Wilson, M.C. (1964) Studies with tritiated digoxin in renal failure. Amer. J. Med. 37, 536.

EliaHOU, H.E. (1964) Mannitol therapy in oliguria of acute onset. Brit. med. J. i, 807.

Eliahou, H.E. \& Bata, A. (1965) The diagnosis of acute renal failure. Nephron, $2,287$.

Etheredge, E.E., Levitin, H., Nakamura, K. \& Glenn, W.W.L. (1965) Effect of mannitol on renal function during open-heart surgery. Ann. Surg. 161, 53.

FinCKH, E.S., JeREMY, D. \& WhYTe, H.M. (1962) Structural renal damage and its relation to clinical features in acute oliguric renal failure. Quart. J. Med. 31, 429.

GANN, D.S. \& WRIGHT, H.K. (1966) Effects of trauma on sodium metabolism and urinary concentrating ability. J. surg. Res. 6, 93 .,

Goldberg, A.H. \& LiLIENField, L.S. (1965) Effects of hypertonic mannitol on renal vascular resistance (30259). Proc. Soc. exp. Biol. (N.Y.), 119, 635.

GotTschalk, C.W. \& MYlle, M. (1957) Micropuncture study of pressures in proximal and distal tubules and peritubular capillaries of the rat kidney during osmotic diuresis. Amer. J. Physiol. 189, 323.

Graber, I.G. \& Sevitr, S. (1959) Renal function in burned patients. J. clin. Path. 12, 25.

Gullick, H.D. \& RAISZ, L.G. (1960) Changes in renal concentrating ability associated with major surgical procedures. New Engl. J. Med. 262, 1309.

HaRrison, C.V., Loughridge, L.W. \& Milne, M.D. (1964) Acute oliguric renal failure in acute glomerulonephritis and polyarteritis nodosa. Quart. J. Med. 33, 39.

Hatcher, C.R. JR, GaGnoN, J.A. \& ClaRke, R.W. (1958) The effects of hydration on epinephrine-induced renal shutdown in dogs. Surg. Forum, 9, 106.

Hoffmeister, F.S., Regelson, W. \& Wilkens, H. (1965) Acute renal failure. Experimental production and prevention. Lab. Invest. 14, 1506.

JAENIKE, J.R. (1966) The renal lesion associated with hemoglobinuria. I. Its production and functional evolution in the rat. J. exp. Med. 123, 523.

Joekes, A.M. \& RellaN, D.R. (1965) Radioactive renography in diagnosis and treatment of acute obstructive renal failure. Lancet, $\mathrm{i}, 96$.

Kennedy, A.C., Gray, M.J.B., Dinwoodie, A.J. \& Linton, A.L. (1961) Removal of urea, creatinine, uric acid, and inorganic phosphate by a rotating-drum artificial kidney. Lancet, ii, 996.

Kennedy, A.C., Linton, A.L., Luke, R.G., Renfrew, S. \& Dinwoodie, A. (1964) The pathogenesis and prevention of cerebral dysfunction during dialysis. Lancet, i, 790.

Kennedy, A.C., Luke, R.G., Linton, A.L., EAton, J.C. \& GraY, M.J.B. (1963a) Results of haemodialysis in severe acute tubular necrosis. A report of 57 cases. Scot. med. J. 8, 97.

Kennedy, A.C., Luke, R.G., Campbell, D. \& Cannon, R.N. (1963b) Combined renal and respiratory failure after trauma. Lancet, ii, 1304.

KERR, W.S., JR (1956) Effects of complete ureteral obstruction in dogs on kidney function. Amer. J. Physiol. 184, 521.

KRAGelUnd, E. (1959) Renal function after major surgery assessed on the basis of the 24 hour creatinine clearance. Acta chir. scand. 117, 416.

Lawrence, J.R., Doig, A., Knight, I.C.S. \& Tothill, P. (1963) Value of '131 I-Hippuran' renography in urological investigation. Brit. med. J. i, 504.

LEVINSKY, N.G. (1966) Management of emergencies. V. Acute renal failure. New Engl. J. Med. 274, 1016.

Levinsky, N.G., Davidson, D.G. \& Berliner, R.W. (1959) Effects of reduced glomerular filtration on urine concentration in the presence of antidiuretic hormone. $J$. clin. Invest. 38, 730.

LindsaY, R.M., Linton, A.L. \& Longland, C.J. (1965) Assessment of postoperative renal function. Lancet, $\mathbf{i}, 978$.

Loughridge, L.W., Milne, M.D., Shackman, R. \& WoolTON, I.D.P. (1960) Clinical course of uncomplicated acute tubular necrosis. Lancet, i, 351.

LUCK, R.J. \& IRVINE, W.T. (1965) Mannitol in the surgery of aortic aneurysm. Lancet, ii, 409.

Luke, R.G., Dinwoodie, A.J., Linton, A.L. \& Kennedy, A.C. (1964) Fructose and glucose tolerance in uremia. J. Lab. clin. Med. 64, 731.

LUKe, R.G., Linton, A.L., Briggs, J.D. \& KenNedy, A.C. (1965) Mannitol therapy in acute renal failure. Lancet, i, 980 .

McGeachie, J. \& Kennedy, A.C. (1963) Simplified quantitative methods for bacteriuria and pyuria. J. clin. Path. 16, 32.

MerRILl, J.P. (1965a) The Treatment of Renal Failure, 2nd edn, p. 202. Heinemann Medical Books, London.

MerRILl, J.P. (1965b) The Treatment of Renal Failure, 2nd edn, p. 128. Heinemann Medical Books, London.

MERRILL, J.P. (1965c) The Treatment of Renal Failure, 2nd edn, p. 92. Heinemann Medical Books, London.

MIELKE, J.E. \& KIRKLIN, J.W. (1966) Renal function during and after surgery. Med. Clin. N. Amer. 50, 979.

Miles, B.E., PATON, A. \& DE WARDEner, H.E. (1954) Maximum urine concentration. Brit. med. J. ii, 901.

Molloy, P.J. (1962) The early diagnosis of impaired postoperative renal function. Lancet, i, 696.

Moore, F.D. (1963) Tris buffer, mannitol and low viscous dextran. Three new solutions for old problems. Surg. Clin. N. Amer. 43, 577.

MUELLER, C.B. (1965) The mechanism of acute renal failure after injury and transfusion reaction and its prevention by solute diuresis. Surg. Clin. N. Amer. 45, 499.

MuncK, O. (1964) Renal circulation in acute renal failure measured with radioactive Krypton ${ }^{85}$ and Xenon ${ }^{133}$. Acute Renal Failure (Ed. by S. Shaldon and G. C. Cook), p. 15. Blackwell Scientific Publications, Oxford.

MURPhy, G.P., Gagnon, J.A. \& Teschan, P.E. (1963a) Measurement of renal function in haemorrhagic hypotension: Effect of mannitol. J. Urol. 90, 133.

MurPhy, G.P., Gagnon, J.A. \& Teschan, P.E. (1963b) Renal haemodynamic effect of mannitol in normotension and hypotension. Surg. Forum, 14, 99.

Nesbit, R.M., Cerny, J.C., HeEtderks, D.R. \& Kendall, A.R. (1962) Acute renal failure: a rationale of treatment and prevention. J. Urol. 88, 331.

Niall, J.F. \& Doyle, J.C. (1966) Treatment with Dextran 40 (Letter). Lancet, i, 817.

O'CoNOR, V.J., Libretti, J.V. \& Grahack, J.T. (1961) The early differential diagnosis of post-operative anuria using the radioactive renogram: an experimental study. J. Urol. 86, 276.

OKen, D.E., ARCE, M.L. \& Wilson, D.R. (1966) Glycerolinduced hemoglobinuric acute renal failure in the rat. I. Micropuncture study of the development of oliguria. J. clin. Invest. 45, 724.

Oliver, J., MacDowell, M. \& Tracey, A. (1951) The pathogenesis of acute renal failure associated with traumatic and toxic surgery, renal ischaemia, nephrotoxic damage and the ischemuric episode. J. clin. Invest. 30, 1307. 
PAK, C.Y. (1963) Mannitol for transfusion reaction. Brit. med.J. i, 1236.

Parsons, F.M. \& McCracken, B.H. (1959) The artificial kidney. Brit. med. J. i, 740.

Perlmutter, M., Grossman, S.L., Rothenberg, S. \& DobKIN, G. (1959) Urine-serum urea nitrogen ratio (simple test of renal function in acute azotemic oliguria). $J$. Amer. med. Ass. 170, 1533.

Platts, M.M. (1966) Electrolyte excretion in uraemia. Clin. Sci. 30, 453.

Powers, S.R., Boba, A., Hostnik, W. \& Stein, A. (1964) Prevention of postoperative acute renal failure with mannitol in 100 cases. Surgery, 55, 15.

RaISz, L.G. \& ScheER, R.L. (1959) Studies on the renal concentrating mechanism. II. Effect of small acute changes in solute excretion. $J$. clin. Invest. 38, 1 .

Reubi, F.C., Gossweller, N., Gurtler, R. \& Huber, A. (1964) The renal blood flow in acute renal failure. Acute Renal Failure (Ed. by S. Shaldon and G. C. Cook), p. 25. Blackwell Scientific Publications, Oxford.

RosCOE, M.H. (1964) Urine in acute and chronic renal failure. Brit. med. J. i, 1084.

SevitT, S. (1959) Pathogenesis of traumatic uraemia. A revised concept. Lancet, ii, 135.

Shackman, R. (1966) Acute renal failure in surgical conditions. Proc. roy. Soc. Med. 59, 37,
Shackman, R., Milne, M.D. \& Struthers, N.W. (1960) Oliguric renal failure of surgical origin. Brit. med.J. ii, 1473. SpINK, W.W. (1962) Endotoxin shock. Ann. intern. Med. $57,538$.

Sporn, N., LANCestremere, R.G. \& PAPPer, S. (1962) Differential diagnosis of oliguria in aged patients. New Engl. J. Med. 267, 130.

SteWART, R.D., BoetTner, E.A., SouthWorth, R.R. \& CERNY, J.C. (1963) Acute carbon tetrachloride intoxication. J. Amer. med. Ass. 183, 994.

Stewart, J.H., TuCKWell, L.A., Sinnett, P.F., Edwards, K.D.G. \& WHYTE, H.M. (1966) Peritoneal and haemodialysis. A comparison of the morbidity and of the mortality suffered by dialysed patients. Quart. J. Med. 35, 407.

Thurau, K. (1964) Renal haemodynamics. Amer.J. Med. 36, 698.

UTZ, D.C. \& HENRY, J.D. (1966) Retroperitoneal fibrosis. Med. Clin. N. Amer. 50, 1091.

Weinstein, L. \& KLAiner, A.S. (1966) Management of emergencies. IV. Septic shock-pathogenesis and treatment. New Engl. J. Med. 274, 950.

Wickham, J.E.A. \& Sharma, G.P. (1965) Endogenous ammonia formation in experimental renal ischaemia. Lancet, i, 195.

Wilkinson, R., Muckle, T.J. \& KerR, D.N.S. (1965) Dextran nephrosis. Proc. Eur. D. \& T. Ass. 11, 320. 